\title{
Identifying the differentiation practices of virtual school teachers
}

\author{
Dennis Beck ${ }^{1} \cdot$ Jennifer Beasley ${ }^{2}$ (D)
}

Received: 21 June 2020 / Accepted: 9 September 2020 / Published online: 8 October 2020

(C) Springer Science+Business Media, LLC, part of Springer Nature 2020

\begin{abstract}
Despite a large increase in enrollments of students in online courses at the K-12 level, there is very little research on the use of differentiation in fully online (called "virtual") schools. This study asked virtual teachers from two different types of schools to discuss their differentiation practices, and compared differentiation practices of teachers across these schools. Nineteen focus groups consisting of 92 teachers were conducted. Data were analyzed using Tomlinson's differentiation framework. Results showed that the large majority of teacher comments about differentiation definitions, assessments, curriculum, grouping and strategies fell in the novice category, and that newer virtual school teachers may struggle in developing skills in differentiation in an online environment.
\end{abstract}

Keywords Differentiation · Virtual schools · Online teaching · Differentiated instruction

\section{Introduction}

Teachers use the principles of differentiation to make decisions that are responsive to the needs of all students (Tomlinson, 2001, 2005). Unfortunately, there is very little research on the use of differentiation in fully online (called "virtual") schools. This is important, because districts employing online education courses have increased enrollments from $50 \%$ to $74 \%$, with rural districts making the most growth (Gemin and Pape 2017). In recent times, a global pandemic forced many educators to teach remotely. In addition, students accessing this technology are more diverse than ever. Enrollment of English language learners (ELL) was higher in 2012-13 (9.2\%) than in the previous ten years (U.S. Department of Education, Office of Special Education Programs,

Jennifer Beasley

jgbeasle@uark.edu

1 University of Arkansas, 102 PEAH, Fayetteville, AR 72701, USA

2 University of Arkansas, 114 PEAH, Fayetteville, AR 72701, USA 
Individuals with Disabilities Education Act (IDEA) 2014). This has resulted in larger online classrooms with more diversity of students. Although there is much research on the effectiveness of differentiation in the brick and mortar K-12 classroom (Baumgartner et al. 2003; Doubet 2007; Valiandes 2015) and on the best practices of how teachers define and enact differentiation (Archambault et al. 1993; Westberg and Daoust 2003), there are few studies found on the use of differentiation in virtual schools. One study found that teachers struggle to find ways to differentiate instruction (Beasley \& Beak, 2017), but beyond that, no research compares differentiation practices of teachers across different types of virtual schools. In order to begin to explore the differentiation practices of virtual teachers, this research will ask the following research questions:

1. How do Virtual School (VS) teachers differentiate teaching practices in an online classroom?

2. How do the differentiation practices of VS teachers compare across diverse kinds of online schools?

\section{Literature review}

\subsection{Differentiated instruction}

A differentiated approach to instruction is informed by principles that include providing high quality curriculum, utilizing flexible grouping, and administering ongoing assessments within a community that respects learning activities that are challenging for all students (Tomlinson, 2001; 2005). Differentiation has often been confused with the term "personalized learning" and for the purposes of this study, it is important to distinguish between the two. DeWaters (2017) stated, "Personalized learning occurs when teachers and students work together to develop a personalized pathway to student learning" (p. 221). DeWaters (2017) claimed personalized learning diverges with differentiation in its highlighting of student interests, needs, readiness, and motivation. This global definition can encompass many instructional methods. In practice, many virtual schools use this term to promote learning that is student selected and student guided. In contrast, differentiated instruction is facilitated by the teacher working in partnership with the student needs. At times, a differentiated lesson may take on the aspects of a personalized learning assignment, but ultimately the learning experiences are guided by learning goals with the teacher facilitating the process (Tomlinson 2017b).

The literature has defined differentiation in practice primarily through research in the traditional face-to-face classroom (Tomlinson, 2001; 2005; Turner and Solis 2017). When observing classrooms, teachers who exhibit fidelity to the model of differentiation a) gather information to tailor instruction to student interest and learning profile as well as readiness to learn the topic or state standard, b) foster classroom community, c) group students flexibly, and d) utilize formative assessment for learning (Doubet 2007). These noted classroom indicators are supported by research in cognitive learning (Bransford et al. 2000). A successful learning community is knowledge-centered (Bransford et al. 2000; Miller \& Hudson, 2006), learner-centered (Ainley, Hidi, \& 
Berndorff, 2002; Bransford et al. 2000; Tomlinson et al. 2003), as well as assessmentcentered (Bransford et al. 2000; Glaser, Chudowsky, Pellegrino, 2001).

Differentiated instruction has been shown to have a positive impact on student achievement (Baumgartner et al. 2003; Doubet 2007). The best practices of teachers who differentiate instruction involve (a) the collection of information about student interests, learning profiles, and student readiness; (b) cultivation of a community in the classroom, (c) distribution of students into groups that can be easily changed based on the activity, and (d) use of formative assessment for learning (Doubet 2007). In differentiated classrooms, community is strengthened through the use of formative assessments that teachers use to determine student readiness, interest and learning profile to access a student's knowledge, skill, and/or understanding during a learning experience. However, there is little research or literature on what differentiation looks like in the virtual school classroom. How do teachers in virtual schools differentiate their instruction, and what does it look like across different types of virtual schools?

During the COVID-19 crisis, many schools required teachers to transition to online instruction (Borup, Jensen, Archambeault, Short, \& Graham, 2020). However, online education has been growing even before this recent crisis, making it important to uncover best practices of differentiation in virtual schools. Key aspects of teaching in a face-to-face classroom may look different online, but it will always be important for teachers to meet the needs of all students (Bransford et al. 2000). In this section we will briefly discuss online education and best practices in online teaching.

\subsection{Online education}

Forty-four of 50 states reported online learning opportunities for K-12 students. Virtual schools have grown both in numbers and in scope of offerings (Gemin and Pape 2017). A virtual school refers to K-12 online learning programs offered fully online by an educational organization where students can earn credit toward graduation or promotion to the next grade level. Despite this growth, evidence for achievement gains in virtual schools is poor (Woodworth, Raymond, Chirbas, Gonzalez, Negassi, Snow, \& Van Donge, 2015; Cremata, Davis, Dickey, Lawyer, Negassi, Raymond, \& Woodworth, 2013). Most research focusing on student achievement in virtual schools has found them to be significantly less effective than brick and mortar schools (Minnesota Office of the Legislative Evaluator, 2011; Woodworth et al., 2015), though at least two studies found greater academic gains than in brick and mortar peers (Wang \& Woodworth, 2011).

With that said, low student achievement is very common in virtual schools. Over four years, Colorado online schools yielded three times more dropouts than graduates. Additionally, the scores of virtual school students' on state tests were, on average, 14 to 26 percentage points below the state average in reading, writing and math (Hubbard\& Mitchell, 2011). Researchers in Ohio examined achievement trends by students' achievement in their prior, comprehensive public school (CPS) and found that students in virtual schools are performing worse on standardized assessments than their peers in traditional charter and traditional public schools (Ahn and McEachin 2017; also Tucker et al. 2011). Technology may offer great 
promise for the future of education, but the data is not showing that it isn't necessarily benefiting virtual schools.

Virtual schools do have potential advantages, such as accommodating schedules and a broader span of courses than may be offered locally. Virtual schools can also serve disabled students who have difficulties attending in-person classes on a regular basis (Miron and Gulosino 2016). Some of the reported benefits of virtual schools include offering convenient lessons that fit a learner's schedule, enabling students who have other obligations during the daytime hours to finish their educational goals, and providing additional time periods for learning. Virtual schools may also act as a shelter for CPS students who have experienced bullying. These advantages may be some of the reasons why virtual schools receive high levels of student, parent and teacher satisfaction. Teaching with a student's needs in mind is at the center of the philosophy of differentiation, which is explained in the next section.

\section{Method}

\subsection{Context of the study}

In this study, three virtual schools located in the mid-southern United States participated in focus group interviews over the course of the 2017-18 academic year. Ninety-two teachers were interviewed using a focus group protocol that was designed to gather information specifically in five categories: 1) Definition; 2) Curriculum; 3) Assessments; 4) Grouping; and 5) Strategies. Approximately 3500 students attended four virtual schools in this mid-southern U.S. state during the 2017-2018 school year. Three of the schools chose to participate in this study - two charters and one district-based. Teachers from these schools were interviewed in focus groups to find out more about their differentiation practices. Table 1 represents the schools included in the study, pseudonyms are used for schools and individual teachers.

The research questions for this study were:

Table 1 Schools and Participants

\begin{tabular}{|c|c|c|c|}
\hline Virtual School & Enrollment & Teachers & Delivery Method \\
\hline $\begin{array}{l}\text { Fillmore } \\
\text { Virtual } \\
\text { School }\end{array}$ & $\begin{array}{l}180 \text { enrolled } \\
\text { studentsK - 12th } \\
\text { grade }\end{array}$ & 20 & $\begin{array}{l}\text { Asynchronous online with options of daily } \\
\text { face-to-face meetings in the school building. }\end{array}$ \\
\hline $\begin{array}{l}\text { Create Virtual } \\
\text { School }\end{array}$ & $\begin{array}{l}772 \text { enrolled students } \\
\mathrm{K}-10 \text { th grade }\end{array}$ & 38 & $\begin{array}{l}\text { Asynchronous online with weekly online live lessons } \\
\text { and occasional face-to-face meetings. }\end{array}$ \\
\hline $\begin{array}{r}\text { Valentine } \\
\text { Virtual } \\
\text { School }\end{array}$ & $\begin{array}{l}2055 \text { enrolled students } \\
\text { K-12th grade }\end{array}$ & 69 & Asynchronous online with weekly online live lessons. \\
\hline
\end{tabular}


1. How do Virtual Schools (VS) teachers differentiate teaching practices in an online classroom?

\section{How do the differentiation practices of VS teachers compare across diverse kinds of online schools?}

\subsection{Participant demographics}

A total of 92 virtual classroom teachers were interviewed from three virtual schools located in the mid-southern United States (Table 1). Of those teachers interviewed, $78 \%$ of the participants self-identified as female and $22 \%$ of the participants self-identified as male. $34 \%$ of the participants reported to have 5 or less years of teaching experience, 22\% reported to have 6-9 years of teaching experience and $44 \%$ reported having 10 or more years of teaching experience. $70 \%$ reported to have less than 3 years of experience teaching online. A total of 18 focus groups were collected over the course of a year. Participants were contacted through the virtual school administration

\subsection{Data collection procedures}

In September 2017, researchers contacted each virtual school and asked permission to interview teachers either face-to-face or online. After obtaining institutional permission, administrators from each school provided dates and times for focus group settings. Both researchers conducted 18 focus groups for all three schools, with a maximum of 6 teachers per group. For this study, 92 teachers from the three schools participated in the focus groups (Table 2)

Focus groups were held with teachers in each school according to their academic subject area or specialty in late February, 2018. The focus group protocol consisted of questions based on results of a previous survey of virtual school teachers' beliefs about differentiation. Researchers chose focus group protocol as a way to verify the results of the survey used in the previous research study. As opposed to an interview, in a focus group discussion, researchers adopt the role of a "facilitator" or a "moderator." This allows the researcher to facilitate or moderate a group discussion between participants and not between the researcher and the participants. Unlike interviews, the researcher thereby takes a peripheral, rather than a center-stage role in a focus group

Table 2 Study Schools, Participants, Focus Groups and Method

\begin{tabular}{llll}
\hline Virtual School & $\begin{array}{l}\text { Participants (compared to } \\
\text { teachers in each school) }\end{array}$ & $\begin{array}{l}\text { Number of } \\
\text { Focus Groups }\end{array}$ & Method \\
\hline Fillmore Virtual School & $8(40 \%)$ & 2 & Face to Face \\
Create Virtual School & $23(61 \%)$ & 6 & Face to Face \\
Valentine Virtual School & $61(88 \%)$ & 10 & Zoom Meeting Room \\
\hline
\end{tabular}


discussion (Bloor et al. (2001); Johnson (1996). After transcription, researchers examined focus group transcripts and code them based on Tomlinson's differentiation work (2017a). The interview protocol consisted of questions based on the teachers' responses at the focus group.

\subsubsection{Instrument}

An interview protocol was created by the researchers in response to findings from a previous study (Beasley \& Beak, 2017). This research revealed that 1) online teachers understood the importance of getting to know their learners, but their practice contradicted that belief, 2) online teachers report that they need to differentiate content, product, and process, and 3) there was little mention of using assessment to inform instruction.

This study built upon the findings of the previous work by focusing on further defining what teachers are doing to differentiate in the classroom, and comparing these practices across types of virtual schools. Questions were centered on the three findings of the previous research (Table 3). The questions were also aligned with the principles of differentiation as defined by the previous research and literature review. This alignment to previous research and literature were important in order to build upon the findings by both the authors and experts in the field. Of particular interest was finding out how virtual teachers are using assessment in their online classroom. The questions were kept purposefully open ended in order to facilitate discussion.

\subsubsection{Data analysis procedures}

Data analysis of focus group transcripts occurred in two phases. First, a Grounded Theory approach (Strauss and Corbin, 1990) was used to code the data set. Developing an initial codebook included the code, a definition of the code, and guidelines for using the code. Afterwards, the researchers used those codes as they analyzed for themes

Table 3 Protocol Questions in Relation to Findings and Principles of Differentiation

\begin{tabular}{|c|c|c|}
\hline Protocol Question & $\begin{array}{l}\text { Relation to } \\
\text { Previous } \\
\text { Finding }\end{array}$ & $\begin{array}{l}\text { Relation to } \\
\text { Principles of } \\
\text { Differentiation }\end{array}$ \\
\hline What is your definition of differentiating instruction? & Finding 1 & \\
\hline $\begin{array}{l}\text { Tell us about the curriculum that you use. } \\
\text { Follow up: What can you change in your curriculum? }\end{array}$ & Finding 2 & $\begin{array}{l}\text { Focused, High Quality } \\
\text { Curriculum* }\end{array}$ \\
\hline $\begin{array}{l}\text { Tell us about assessments in your online classroom. } \\
\text { Follow up: In what ways do you use assessment? How does } \\
\quad \text { assessment data change the way you address your students' needs? }\end{array}$ & Finding 3 & Ongoing Assessments* \\
\hline $\begin{array}{l}\text { In what ways do you group students in your online classroom. } \\
\text { Follow up: How do you build community in the classroom? }\end{array}$ & Finding 2 & $\begin{array}{l}\text { Flexible Instructional } \\
\text { Arrangements* }\end{array}$ \\
\hline $\begin{array}{l}\text { What teaching strategies help you to address the diverse needs of your } \\
\text { students? }\end{array}$ & Finding 2 & Respectful Tasks* \\
\hline $\begin{array}{l}\text { Follow up: What technology tools have been helpful in addressing } \\
\text { your students' needs? }\end{array}$ & & \\
\hline
\end{tabular}

*Based upon the work of Tomlinson (2017a, 2017b) 
from the participants' responses. The goal was to reach categorical saturation (Lincoln \& Guba, 1986). A confirmatory analysis was also conducted through the use of a second coder. We then adapted Hedrick's “Ascending Levels of Intellectual Demand (2005) for differentiation as a coding scheme for understanding how novices transition to apprentice, practitioner, and expert levels. Hedrick's (2005) original framework looked at ways that educators grow in their understanding and application of differentiation in brick and mortar classrooms and this was considered as we identified ways teachers spoke about their use of differentiation in virtual classrooms (Fig. 1).

Due to the lack of literature when it comes to how differentiation is being applied and defined in K-12 VSs, the researchers applied the Ascending Levels of Intellectual Demand (AID) to participant responses. For this study, novices were noted by their lack of clarity of definition and application of differentiation. They tended to teach as if the whole class were the same. Apprentices were more likely to tolerate some ambiguity and begin to see groups of students with similar needs. Practitioners were able to apply the principles of differentiation in multiple ways

\begin{tabular}{|c|c|c|c|c|}
\hline Item & Novice & Apprentice & Practitioner & Expert \\
\hline 1 & $\begin{array}{l}\text { Unsettled by the } \\
\text { ambiguous and organic } \\
\text { nature of differentiation }\end{array}$ & $\begin{array}{l}\text { Tolerates the ambiguous } \\
\text { nature of differentiation }\end{array}$ & $\begin{array}{l}\text { Accepts the ambiguous } \\
\text { nature of differentiation }\end{array}$ & $\begin{array}{l}\text { Skillfully differentiates } \\
\text { curriculum } \\
\text { and instruction through } \\
\text { the } \\
\text { development of } \\
\text { curriculum }\end{array}$ \\
\hline 2 & $\begin{array}{l}\text { Seeks algorithmic } \\
\text { processes and expects } \\
\text { "mastery" of differentiation }\end{array}$ & $\begin{array}{l}\text { Understands the } \\
\text { philosophy of } \\
\text { differentiation but lacks } \\
\text { confidence in application }\end{array}$ & $\begin{array}{l}\text { Demonstrates accuracy and } \\
\text { confidence in explaining } \\
\text { differentiation of curriculum } \\
\text { and instruction }\end{array}$ & $\begin{array}{l}\text { Models differentiation } \\
\text { with fluency and } \\
\text { flexibility in staff } \\
\text { development and } \\
\text { teaching situations }\end{array}$ \\
\hline 3 & $\begin{array}{l}\text { Focuses on the challenges } \\
\text { instead of the benefits/ } \\
\text { necessity }\end{array}$ & $\begin{array}{l}\text { Acknowledges gaps in } \\
\text { personal understanding } \\
\text { and } \\
\text { skills with differentiating } \\
\text { curriculum and instruction }\end{array}$ & $\begin{array}{l}\text { Makes connections among } \\
\text { various methods within a } \\
\text { discipline in order to } \\
\text { facilitate } \\
\text { differentiation }\end{array}$ & $\begin{array}{l}\text { Problem solves in } \\
\text { situations where } \\
\text { differentiation is both } \\
\text { necessary and difficult }\end{array}$ \\
\hline 4 & $\begin{array}{l}\text { Seeks solutions that are } \\
\text { already part of a repertoire } \\
\text { of strategies instead of } \\
\text { redefining the nature of } \\
\text { curriculum and instruction }\end{array}$ & $\begin{array}{l}\text { Makes surface level } \\
\text { connections between } \\
\text { differentiation and other } \\
\text { models/strategies inherent } \\
\text { in good } \\
\text { curriculum/instruction }\end{array}$ & $\begin{array}{l}\text { Understands the connections } \\
\text { among content, process, } \\
\text { product, and learning } \\
\text { environment when } \\
\text { differentiation is achieved in } \\
\text { the areas of readiness, } \\
\text { interest, and learning profile } \\
\text { (or any } \\
\text { combination of the areas) }\end{array}$ & $\begin{array}{l}\text { Articulates the rationale, } \\
\text { philosophy, and "how to" } \\
\text { of differentiation to a } \\
\text { wide variety of audiences } \\
\text { (e.g. parents, teachers, } \\
\text { students, } \\
\text { administrators) }\end{array}$ \\
\hline 5 & $\begin{array}{l}\text { Identifies the challenges } \\
\text { inherent in high prep } \\
\text { differentiation (grading } \\
\text { major projects) instead of } \\
\text { focusing on low prep } \\
\text { possibilities }\end{array}$ & $\begin{array}{l}\text { Demonstrates a } \\
\text { willingness to work } \\
\text { through challenges } \\
\text { with some persistence }\end{array}$ & $\begin{array}{l}\text { Exhibits a belief in } \\
\text { differentiation, but lacks } \\
\text { confidence at times in } \\
\text { addressing challenges }\end{array}$ & $\begin{array}{l}\text { Uses various methods } \\
\text { from a variety of } \\
\text { disciplines in order to } \\
\text { facilitate the } \\
\text { differentiation of } \\
\text { curriculum and } \\
\text { instruction }\end{array}$ \\
\hline 6 & $\begin{array}{l}\text { Lacks a big picture } \\
\text { understanding of the } \\
\text { philosophy due to } \\
\text { misperceptions about good } \\
\text { curriculum/instruction (e.g. } \\
\text { assessment and evaluation) }\end{array}$ & $\begin{array}{l}\text { Distinguishes between a } \\
\text { good } \\
\text { curriculum/instruction } \\
\text { and that which is } \\
\text { differentiated }\end{array}$ & $\begin{array}{l}\text { Recognizes and avoids the } \\
\text { "quick fixes" to } \\
\text { differentiating curriculum } \\
\text { and } \\
\text { instruction }\end{array}$ & $\begin{array}{l}\text { Exhibits an unyielding } \\
\text { belief in the necessity of } \\
\text { differentiation for all } \\
\text { students }\end{array}$ \\
\hline 7 & $\begin{array}{l}\text { Lacks persistence and a } \\
\text { willingness to work at } \\
\text { understanding/application }\end{array}$ & $\begin{array}{l}\text { Asks thoughtful questions } \\
\text { about both the philosophy } \\
\text { and the application }\end{array}$ & & $\begin{array}{l}\text { Seeks new methods that } \\
\text { will facilitate refinement } \\
\text { in the differentiation of } \\
\text { curriculum and } \\
\text { instruction }\end{array}$ \\
\hline 8 & & $\begin{array}{l}\text { Can accurately explain } \\
\text { differentiation as a } \\
\text { concept }\end{array}$ & & $\begin{array}{l}\text { Understands there is } \\
\text { much left to learn in the } \\
\text { area of differentiation }\end{array}$ \\
\hline
\end{tabular}

Fig. 1 Ascending Levels of Intellectual Demand: Differentiation 
and begin to utilize assessment data to change assignments for varying groups of students. Finally, experts were able to begin to see students individually and plan proactively on a consistent basis. Further characteristics are discussed for each level (e.g. "Unsettled by the ambiguous nature of differentiation" in Novice level) and thus developed a coding scheme that described how each of these descriptions looked in a VS. Focus group transcripts were coded using this scheme.

\section{Results on research question 1: How do VS teachers differentiate teaching practices in an online classroom?}

The interviews resulted in findings that were categorized by levels of differentiation but also allowed researchers to hear about the practices of virtual teachers. Salient quotes were identified to communicate the findings in the area of 1) Defining differentiation,

2) Curriculum, 3) Grouping, 4) Teaching Strategies, and 5) Assessment.

Similar to the initial research, VS teachers' definitions were more novice in nature. VS Teachers spoke about differentiation being "different for different students" (Novice, item 6). A quote by one teacher exemplified this, “...differentiation to me, I think it's about the root word...to be different. If you are differentiating you're cooking outdoors, then you make changes to your cooking that make it look different than cooking in a kitchen" (VS 1, Creative School). A more expert level response was demonstrated by two VS teachers, "...differentiating is based a lot on the relationships you build with the students. We learn about their past educational experiences, what their goals are for the future, and what obstacles might be in their path so that you can modify and adjust the way that you present material and help them to engage" (VS 2, Creative School).

Many of the responses to curriculum in a differentiated classroom sought solutions that were already a part of their existing repertoire (Novice, item 4). Very few VS teachers made connections across disciplines or saw ways to modify content, process, or product. One teacher from Filmore Virtual school noted, "I differentiate my lesson by changing the number of examples I give students who are farther along in the lesson. I also reduce the number of answers in a multiple choice for struggling students." A more practitioner level response demonstrated, "I look at my curriculum and see where students are both content wise, but also engagement wise. I try to engage student personal interests - and that looks different in different disciplines" (VS 1, Filmore School).

In the area of grouping, there were fewer comments than other categories. Of the 139 distinct quotes examined as a part of this study, 24 directly correlated to grouping. This may be that many of the school LMS systems did not allow many types of grouping strategies, or it could have been due to the fewer number of students in the "live sessions." As with other categories, the majority of VS teachers situated themselves within the novice level, primarily item 3 that focuses on challenges instead of benefits. One example was, "I don't necessarily group, but I do allow them to chat with one another through our social discussion groups" (VS 3, Filmore School). Another identified this as an area for improvement, "If they don't call in, they don't show up, so they're not part of any grouping. I think this is my downfall" (VS 3, Creative School). 
Teaching strategies noted by the teachers were typically categorized by what they did when they were brick and mortar teachers (Novice, item 4). An example of this was by a teacher from the Valentine School, “...sometimes you just revert back to some of the tools that you had when you were in a face-to-face classroom - like I would put a math problem up on the whiteboard and discuss the answer." One VS teacher had a more expert level answer (one that models differentiation with flexibility and fluency): "I really set out to gamify my class and it has done a world of good. My students have made so many gains both in engagement and academically" (VS 4 Filmore School).

The area of assessment was more informative than in our last research study (Beasley \& Beak, 2017), representing 32\% of the quotes being analyzed. Previously, we found that very few VS teachers spoke about how they used assessment in a differentiated classroom. However, during this study's focus groups, one teacher noted "...sometimes we have to dig a little deeper -it's not exactly what it says when you first look at data- you have to start to talk with kiddos to find out what they need in our classroom" (VS 8, Creative School). Another answer that identified at a more practitioner level (item 4) was: "I would say that most of the time (assessment) helps me to understand that a student may have to show me their answer in more than one way - not just a written answer" (VS 3, Creative School).

\section{Results for research question 2: How do the differentiation practices of VS teachers compare across diverse kinds of online schools?}

The results of the comparison of differentiation practices using these levels of differentiation are presented in Table 4. The numbers in each cell represent the number of times that teachers in each school mentioned something that was coded as a definition, assessment, grouping, or strategy, and at which level. For all three virtual schools, the vast majority of teacher comments about differentiation definitions, assessments, curriculum, grouping and strategies fell in the novice category. Teachers who made these statements showed evidence of being new or inexperienced to differentiated instruction. Also, all three schools show a reduced, but still robust presence of comments in the apprentice column. This means that these teachers shared comments that showed that they knew more about differentiation of instruction and practiced it more than did novices, but still fell short of regular practice and expertise.

An interesting contrast is found when comparing Filmore Virtual (district-based charter school) teachers' responses to that of the other schools at the Practitioner or Expert level for Definitions, Assessments, Grouping, and Strategies. Filmore teachers had $0 \%$ of their responses coded at the Practitioner and Expert levels, while Create and Valentine Virtual schools had higher levels of differentiation. However, Filmore Virtual school did show evidence of differentiation in the curriculum category at the practitioner and expert levels.

Another item that stands out in the data is that Valentine Virtual school appears to have much more expertise in their definitions of differentiation, which you might expect from the oldest statewide virtual school. Also of note is that Create Virtual school appeared to have the most evenly spread distribution of comments about differentiation across the Apprentice, Practitioner, and Expert levels of differentiation in all of the categories of differentiation. Comparing differentiated 
Table 4 Comparing Differentiation Practices Within and Across Virtual Schools

\begin{tabular}{|c|c|c|c|c|c|c|c|c|c|c|c|c|}
\hline & \multicolumn{4}{|c|}{ Filmore Virtual School } & \multicolumn{4}{|c|}{ Create Virtual School } & \multicolumn{4}{|c|}{ Valentine Virtual School } \\
\hline & $\mathrm{N}$ & A & $\mathrm{P}$ & $\mathrm{E}$ & $\mathrm{N}$ & $\mathrm{A}$ & $\mathrm{P}$ & $\mathrm{E}$ & $\mathrm{N}$ & A & $\mathrm{P}$ & $\mathrm{E}$ \\
\hline Definitions & 57 & 43 & 0 & 0 & 65 & 16 & 5 & 14 & 68 & 11 & 21 & 13 \\
\hline Assessments & 78 & 22 & 0 & 0 & 53 & 18 & 21 & 9 & 79 & 9 & 7 & 5 \\
\hline Curriculum & 50 & 16 & 16 & 16 & 60 & 21 & 15 & 4 & 76 & 21 & 3 & 0 \\
\hline Grouping & 67 & 33 & 0 & 0 & 55 & 29 & 13 & 3 & 74 & 6 & 20 & 0 \\
\hline Strategies & 100 & 0 & 0 & 0 & 72 & 10 & 14 & 4 & 61 & 31 & 5 & 3 \\
\hline
\end{tabular}

Differentiation categories, $\mathrm{N}=$ Novice; $\mathrm{A}=$ Apprentice; $\mathrm{P}=$ Practitioner; $\mathrm{E}=$ Expert.

instruction practices across schools by category is helpful in terms of considering some of the larger impacts of different types of virtual schools, but it does little to provide information on the more granular differentiated instruction practices of virtual school teachers.

\section{Discussion on research question 1: How do VS teachers differentiate teaching practices in an online classroom?}

As stated previously, the large majority of teacher comments about differentiation definitions, assessments, curriculum, grouping and strategies fell in the novice category. Also, all three schools show a reduced, but still robust presence of comments in the apprentice column. This falls in line with current statistics showing that virtual schools have grown both in numbers and in scope of offerings (Gemin and Pape 2017). Such large growth would most likely result in a large number of teachers who are untrained in online instruction. This also confirms research by Kennedy and Archambeault (2015) about the lack of teacher training to teach online, as well as the lack of training in how to lead and administrate instruction online. As seen in this study, this lack of confidence to differentiate is also in line with literature in the field. The most recent U.S. Survey on Preparation (Bowsher, Sparks, and Hoyer, 2018) reported that $47 \%$ of teachers in their first year of teaching felt unprepared to differentiate instruction in the classroom. This same report noted that early career teachers need common planning times and regular support in order to increase in expertise. Unless time is given for virtual teachers to receive professional development in differentiation, movement towards expertise may be impeded.

Many of the virtual school teachers' responses to curriculum in a differentiated classroom sought solutions that were already a part of their existing repertoire and had difficulty flexibly grouping. This confirms research by Dixon, Yssel, McConnell \& Hardin (2014) that when adopting new strategies and techniques, teachers need multiple experiences to build efficacy. This literature suggests that novice teachers start by adopting new routines before working on more high preparation strategies or adjusting curriculum. It also supports research from the diffusion of innovations field that discusses the sometimes lengthy process that most people go through before they fully adopt an innovation as paradigm-shifting as the differentiation process (Rogers 2003). Flexibility of instruction is another obstacle that is 
prevalent in the literature on differentiation (Doubet 2007; Tomlinson 1999; Tomlinson et al. 2003). In this study, VS teachers struggled to think of grouping strategies within the confines of their classroom.

This study provided a look into the use of assessment in the differentiated classroom. It was revealing here to focus on what the few teachers who identified at a practitioner or expert level said about assessment. They focused on finding multiple means to assess student understanding and digging deeper to determine student needs. This corroborates research by Tomlinson and Moon (2013) that stresses assessment as imperative to differentiation. Without knowing where students are, it is impossible to chart a personalized course for each student to reach the lesson's goals. Although VS teachers were not utilizing assessment in the same way, all identified it as fundamental to differentiating instruction.

\section{Discussion on research question 2: How do the differentiation practices of VS teachers compare across diverse kinds of online schools?}

A result that was mentioned previously was the comparison of Filmore Virtual (districtbased charter school) teachers' responses to that of the other schools at the Practitioner or Expert level for Definitions, Assessments, Grouping, and Strategies. This confirms previous research with virtual school teachers in the area of assessment (Beasley \& Beak, 2017). Filmore teachers had $0 \%$ of their responses coded at the Practitioner and Expert levels, while Create and Valentine Virtual schools had higher levels of differentiation. Recalling that Filmore Virtual's is a new virtual school may help interpret this data. As a new virtual school that is district based, Filmore Virtual has used its own brick and mortar teachers as online course instructors. As a result, the relative inexperience of Filmore's teachers with online learning may be the reason that they showed no evidence of differentiation at the practitioner or expert levels. However, Filmore Virtual did show evidence of differentiation in the curriculum category at the practitioner and expert levels. This may be due to a widespread belief among virtual school administrators that when a school first begins to provide online courses, there is overreliance on the online courses to differentiate instruction. This may also be due to research in differentiation that indicates that the act of differentiating is a highly nuanced skill that requires embedded training. Tomlinson (1999) states: "For all its promise ... effective differentiation is complex to use and thus difficult to promote in schools. Moving toward differentiation is a long-term change process" (p. 6). As a result, Filmore Virtual school teachers may be experiencing this long-term change process that Tomlinson describes.

To help move novice teachers along the continuum towards expertise, teachers may need to learn more about the strengths of virtual schools in finding ways to respond to student needs. In the beginning, virtual school teachers will need to know about and help students to take advantage of such things as accommodating schedules and a broader span of courses than other schools can potentially increase student engagement by pairing students with courses that are a good match for them while allowing them to take them at their own pace. They can also equip disabled students who have frequent medical appointments to attend virtual school classes and complete assignments on time. As teachers grow in their knowledge of differentiation, they can begin to learn 
more about how the community of virtual schools can act as a shelter for CPS students who have experienced bullying. Virtual school teachers can begin to weave community building, curriculum and assessment with flexible instructional decisions to accommodate for student differences. These advantages may be some of the reasons why virtual schools receive high levels of student, parent and teacher satisfaction compared to CPS.

Another result mentioned that Valentine Virtual school appears to have much more expertise in their definitions of differentiation, which you might expect from the oldest statewide virtual school. Many of the larger virtual school providers have defined programs of professional development for their teachers, and Valentine virtual is included in this program (Gemin and Pape 2017). They have a professional development (PD) program for all teachers that includes their own approach to best practices for online teaching. This PD program appears to have been successful in helping teachers understand the definition of differentiated instruction. This confirms what Tomlinson and Allan (2000) have suggested, that an educational leader may first want to assist teachers in defining differentiation as a first step to understanding what it is and is not. As virtual teachers begin to grow, leaders need to ensure that a common definition is identified. However, according to our data, this experience and training has apparently only been implemented successfully in the grouping category, but not in assessments, curriculum or strategy. Although it is promising that Valentine Virtual teachers possess expertise in defining differentiation and in grouping, it is concerning that it hasn't impacted assessments, curriculum, or strategy, particularly because of these areas' proven impact on student achievement (Baumgartner, Lipowski, \& Rush, 2003; Doubet 2007), and particularly on student performance on standardized assessments (Ahn and McEachin 2017; also Tucker et al. 2011).

In the study, Create Virtual school appeared to have the most evenly spread distribution of comments about differentiation across the Apprentice, Practitioner, and Expert levels of differentiation in all of the categories of differentiation. There may be many reasons for this even distribution, but one could be due to the hiring practices at Create Virtual school, which appear to focus on hiring more experienced teachers regardless of whether they have online experience. This hiring practice may have resulted in Create Virtual school teachers who are experienced with differentiating instruction in brick and mortar environments and who are learning to apply similar principles in online learning environments. It could also point to the ability to transfer differentiation skills across different kinds of learning environments, something that could increase quality of instruction in online schools, which is sorely needed (Woodworth et al., 2015; Cremata et al., 2013). Comparing differentiated instruction practices across schools by category is helpful in terms of considering some of the larger impacts of different types of virtual schools, but it does little to provide information on the more granular differentiated instruction practices of virtual school teachers.

\section{Limitations of the study}

In this study, there were limitations that may have impacted the results. The small sample size of virtual classroom teachers does not allow the researchers to generalize across all contexts. Another limitation was the instrument used to identify novices to experts in differentiation. The subjectivity of the AID when analyzing participant responses may have resulted in errors. Finally, the lack of research in the topic does 
not allow for corroboration with other experts in the field. Increasing the number of participants in the future may enhance the generalizability of the findings.

\section{Conclusions}

Research on the practice of differentiation is ongoing, both in the brick and mortar school as well as the virtual school. This research helped to reveal the differentiation practices of teachers across different types of virtual schools. It also made clearer some of the differences between the differentiation practices of expert online teachers and those who are less than expert. This is significant because little research has been done to discover the expert differentiation practices of online teachers. Discovery of these practices should help to create professional development for all online teachers that is focused on building teachers skills in differentiation specific to the online learning environment. Continued research on professional development in differentiation can reveal the connection between differentiation and increased online teacher efficacy (Dixon et al. 2014).

Previous research in virtual schools has found that teachers struggle to find ways to differentiate instruction. For example, it has shown that online teachers report that they need to differentiate content, product, and process, and also comprehend the importance of learner profiles. However, their practice contradicts their beliefs. Actual practice shows that they do not use learner profiles as part of differentiation, and there is little mention of the use of assessment to inform instruction. The current study showed that newer virtual schools may struggle to acquire teachers who differentiate instruction at the practitioner and expert level. This points to a need to further investigate the instructional practices of the teachers who were practitioners and experts in the different categories of differentiation. Future research should explore these expert and practitioner practices and seek to develop professional development interventions that are effective in helping teachers to differentiate instruction at these higher levels. A follow up study is planned where teachers whose responses demonstrated practitioner or expert levels of differentiation (Tomlinson 2017a, 2017b) will be invited to participate in a follow up interview that focuses on better understanding their expertise in differentiating instruction in a virtual school.

The current study also showed that even experienced virtual schools may be effective in one area of differentiated instruction yet fail to deliver in others. Other research has shown that obstacles to differentiation may be technological, instructional, administrative, and organizational in nature (Aldossari 2018; Doubet 2007). Future research should investigate what kind of obstacles may be hindering application of differentiated instruction in the areas of assessment, curriculum, and strategies, as well as considering potential solutions to overcome these obstacles. If curricular or technological obstacles to differentiation of instruction exist, curriculum and software designers should consider how to remove those obstacles while maintaining other development priorities. Additionally, future research can examine how schools can partner with designers and developers of online curriculum to allow for maximum differentiation. 
Funding The research was not supported through grants or outside funding.

\section{Compliance with ethical standards}

Conflict of interest Jennifer G. Beasley declares that she has no conflict of interest.

Dennis Beck declares that he has no conflict of interest.

Compliance with ethical standards IRB Protocol Approval \#1709071625.

\section{References}

Ahn, J., \& McEachin, A. J. (2017). Student enrollment patterns and achievement in Ohio's online charter schools. Educational Researcher, 46(1), 44-57.

Ainley, M., Hidi, S., \& Berndorff, D. (2002). Interest, learning, and the psychological processes that mediate their relationship. Journal of Educational Psychology, 94(3), 545-561. https://doi.org/10.1037/00220663.94.3.545

Aldossari, A. T. (2018). The challenges of using the differentiated instruction strategy: A case study in the general education stages in Saudi Arabia. International Education Studies, 11(4), 74-83.

Archambault, F. X., Westberg, K. L., Brown, S. W., Hallmark, B. W., Emmons, C. L., \& Zhang, W. (1993). Regular classroom practices with gifted students: Results of a national survey of classroom teachers. (Research Monograph 93102). Storrs, CT: The University of Connecticut.

Baumgartner, T., Lipowski, M, B., \& Rush, C. (2003). Increasing reading achievement of primary and middle school students through differentiated instruction. Available from Education Resources Information Center (ERIC No. ED479203)

Beasley, J.G., \& Beck, D. (2017). Defining differentiation in cyber schools: What online teachers say. TechTrends, 61(6), 1-10.

Bloor, M., Frankland, J., Thomas, M., \& Robson, K. ( 2001). Focus groups in social research. Thousand Oaks, CA: Sage Publications Inc. Borup, J., Jensen, M., Archambault, L., Short, C.R. \& Graham, C.R. (2020). Supporting Students During COVID-19: Developing and Leveraging Academic Communities of Engagement in a Time of Crisis. Journal of Technology and Teacher Education, 28(2), 161-169. Waynesville, NC USA: Society for Information Technology \& Teacher Education. Retrieved June 9, 2020 from https:/www.learntechlib.org/primary/p/216288/.

Bowsher, A., Sparks, D., \& Hoyer, K. M. (2018). Preparation and support for teachers in public schools: Reflections on the first year of teaching. Stats in Brief, NCES, 2018-143, 1-36.

Borup, J., Jensen, M., Archambault, L., Short, C.R. \& Graham, C.R. (2020). Supporting Students During COVID-19: Developing and Leveraging Academic Communities of Engagement in a Time of Crisis. Journal of Technology and Teacher Education, 28(2), 161-169.

Bransford, J. D., Brown, A. L., \& Cocking, R. R. (2000). How people learn: Brain, mind, experience, and school. Washington, DC: National Academies Press.

Cremata, E., Davis, D., Dickey, K., Lawyer, K., Negassi, Y., Raymond, M., \& Woodworth, J. (2013). National charter school study: Research Report. Retrieved from CREDO at Stanford University: http:// credo.stanford.edu/documents/NCSS.

DeWaters, C. (2017). Getting personalization right. The Reading Teacher, 71(2), 221-224.

Dixon, F., Yssel, N., McConnell, J., \& Hardin, T. (2014). Differentiated instruction, professional development, and teacher efficacy. Journal for the Education of the Gifted, 37(2), 111-127.

Doubet, K, J. (2007). Teacher fidelity and student response to a model of differentiation as implemented in one high school (Order No. 3283287). Available from ProQuest Dissertations \& Theses Global. (304806872). Retrieved from http://0-search.proquest.com.library.uark.edu/docview/304806872?accountid=8361

Gemin, B., \& Pape, L. (2017). Keeping Pace with K-12 Online Learning, 2016. Evergreen Education Group.

Glaser, R., Chudowsky, N. and Pellegrino, J.W., Eds. (2001) Knowing What Students Know. The Science and Design of Educational Assessment. National Academies Press, Washington DC.

Hedrick, K. (2005). Ascending levels of intellectual demand within and beyond the parallel curriculum model. In C. Tomlinson, S. Kaplan, \& J. Purcell (Eds.), The Parallel Curriculum Model: Essays for Application Across the Content Areas K-12. Thousand Oaks, CA: Corwin Press.

Hubbard, B., \& Mitchell, N. (2011). Troubling questions about online education. Colorado: EdNews. 
Hudson, P. \& Miller, S. (2006). Designing and implementing mathematics instruction for students with diverse learning needs. Boston, MA: Pearson Education.

Johnson, A. (1996). It is good to talk': The focus group and the sociological imagination. The Sociological Review, 44, 517-538.

Minnesota Office of the Legislative Auditor, September 2011, K-12 Online Learning Evaluation Report Summary.

Miron, G., \& Gulosino, C. (2016). Virtual schools report 2016. Boulder, CO: National Education Policy Center.

Rogers, E. M. (2003). The diffusion of innovation (5th ed.). Free Press.

Tomlinson, C. A. (1999). Leadership for differentiated classrooms. The School Administrator, 56(9), 6-11.

Tomlinson, C. A. (2017a). How to differentiate instruction in academically diverse classrooms (3rd ed.). Alexandria, VA: Association for Supervision and Curriculum Development.

Tomlinson, C. A. (2017b). Let's celebrate personalization: But not too fast. Educational Leadership, 74(6), $10-15$.

Tomlinson, C. A. (2001). How to differentiate instruction in mixed-ability classrooms (2nd ed.). Alexandria, VA: Association for Supervision and Curriculum Development.

Tomlinson, C.A. (2005). An educator's guide to differentiating instruction. Houghton Mifflin: Boston, MA.

Tomlinson, C. A., \& Allan, S. D. (2000). Leadership for differentiating schools and classrooms. Alexandria, VA: ASCD.

Tomlinson, C. A., Brighton, C., Hertberg, H., Callahan, C. M., Moon, T. R., Brimijoin, K., et al. (2003). Differentiating instruction in response to student readiness, interest, and learning profile in academically diverse classrooms: A review of literature. Journal for the Education of the Gifted, 27(2/3), 119-145.

Tomlinson, C. A., \& Moon, T. R. (2013). Assessment and student success in a differentiated classroom. Alexandria, VA: Association for Supervision and Curriculum Development.

Tucker, B., Dillon, E., \& Jambulapati, P. (2011). Ohio E-Schools: Learning from their experience. Education Sector. Retrieved June 26, 2013 from http://www.educationsector.org/publications/ohio-e-schoolslearning-their-experience

Turner, W., \& Solis, O. (2017). The misnomers of differentiating instruction in large classes. The Journal of Effective Teaching, 17(3), 64-76.

U.S. Department of Education, Office of Special Education Programs, Individuals with Disabilities Education Act (IDEA) 2014 database, retrieved October 3, 2014, from https://inventory.data.gov/dataset/8715a3e8bf48-4eef-9deb-fd9bb76a196e/resource/a68a23f3-3981-47db-ac75-98a167b65259. See Digest of Education Statistics 2014, table 204.30.

Valiandes, S. (2015). Evaluating the impact of differentiated instruction on literacy and reading in mixed ability classrooms: Quality and equity dimensions of education effectiveness. Studies in Educational Evaluation, 45, 17-26.

Wang, H., \& Woodworth, K. (2011). Evaluation of Rocketship education's use of DreamBox Learning's Online Mathematics Program.

Westberg, K, L., \& Daoust, M, E. (2003). The results of the replication of the classroom practices survey in two states. The National Research Center on the Gifted and Talented. Retrieved from: http://www.gifted. uconn.edu/nrcgt/newsletters/fall03/fall032.html

Woodworth, J. L., Raymond, M. E., Chirbas, K., Gonzalez, M., Negassi, Y., Snow, W., \& Van Donge, C. (2015). Online charter school study 2015. Center for Research on Educational Outcomes.

Publisher's note Springer Nature remains neutral with regard to jurisdictional claims in published maps and institutional affiliations. 